\title{
İşyerinde Sağlığın Korunması ve Teşvikine Yönelik Uygulamalar ile Çalışanların Kurumsal Yemek Hizmetlerinden Memnuniyet Durumlarının Değerlendirilmesi
}

\author{
Health Promoting Applications in Workplace and Evaluation of Employee Satisfaction with \\ Catering Services
}

\author{
Betül Kocaadam Bozkurt' ${ }^{1}$, Saniye Bilici² ${ }^{2}$ Emine Yassıbaş ${ }^{3}$, Hande Mortaş ${ }^{4}$, Eda Köksal ${ }^{5}$
}

Geliş tarihi/Received: 19.11.2020 • Kabul tarihi/Accepted: 23.12.2020

\section{ÖZET}

Amaç: Çalışan bireylerin kurumsal yemek hizmetlerinden memnuniyet durumlarının, tüketici memnuniyetini belirleyen faktörleri ve işyerinde sağlığın korunması ve teşvikine yönelik uygulamaların değerlendirilmesi amaçlanmıştır.

Bireyler ve Yöntem: Araştırmanın örneklemini, Ankara ilinde bulunan farklı kamu kurumlarında çalışan 18-65 yaş aralığında 290 erkek (\%43.5), 376 kadın (\%56.5) olmak üzere 666 kamu çalışanı oluşturmaktadır. Veriler, anket aracılığıyla elde edilmiştir. Katılımcıların kurumsal yemek hizmetlerinden memnuniyet durumlarının değerlendirilmesi amacıyla 39 soruluk bir memnuniyet anketi oluşturulmuştur. Anket puanları, 60 puanın altı 'yetersiz', 60-74 puan 'orta', 75-84 puan 'iyi', $\geq 85$ puan ise 'çok iyi' olarak sınıflandırılmıştır. Oluşturulan memnuniyet anketinin iç tutarlılığı 0.88 olarak belirlenmiştir.

Bulgular: Bireylerin yemek hizmetlerinden memnuniyetini etkileyen en önemli ilk üç faktör sırasıyla hijyen (\%79.7), besin kalitesi (\%78.5) ve menüde yer alan yemeklerin çeşitliliğidir (\%51.2). Yemek hizmetlerinden memnuniyet puanının 65.8 \pm 11.87 (orta düzey) olduğu ve puanın kadınlara kıyasla erkeklerde yüksek olduğu belirlenmiştir ( $<<0.05$ ). Memnuniyet durumunu 'çok iyi’ olarak değerlendiren bireylerin sıklığı \%5.7 iken yetersiz sınıfında yer alan bireylerin sıklığı \%31.7’dir. Çalışanlar, kurumların \%82.0'sinde sağlıklı beslenmeyi teşvik eden uygulamaların olmadığını, \%69.0’unda sağlığın korunması ve teşvikine yönelik faaliyetler için potansiyel olanakları sunmadığını belirtmişlerdir. Kurumlarda, sağlıklı beslenmeyi teşvik etmeye yönelik hizmetler arasında en sık görülen üç hizmetin el yıkama için elverişli imkânlar (\%79.4), tüm çalışanlar için içme suyuna erişim (\%67.0), personel yemekhanesinde sunulan sağlıklı yemek seçenekleri (\%37.1) olduğu belirlenmiştir.

Sonuç: Sonuçlar, kurumlarda yemek hizmetlerine yönelik standartların uygulanması, çalışanların yemek hizmetlerinden memnuniyetini arttırmak adına yemeklerde lezzetin, kalitenin ve çeşitliliğin arttırılması gerekliliğini göstermektedir. Bu doğrultuda işyerleri, T.C. Sağlık Bakanlığı’nın menü planlama ve sağlıklı beslenmeye yönelik rehberlerini uygulamalıdır. Personelin sağlıklı beslenmesi ve fiziksel aktivitesinin arttırılmasına yönelik planlanacak uygulamalar personel sağlığı, motivasyonu ve verimliliği üzerine olumlu etkiler sağlayacaktır.

Anahtar kelimeler: Kurumsal yemek hizmetleri, tüketici memnuniyeti, işyerinde sağllğın korunması

1. İletişim/Correspondence: Erzurum Teknik Üniversitesi, Sağlık Bilimleri Fakültesi, Beslenme ve Diyetetik Bölümü, Erzurum, Türkiye

E-posta: betulkocaadam@gmail.com • — https://orcid.org/0000-0002-9058-4630

2. Gazi Üniversitesi, Sağllk Bilimleri Fakültesi, Beslenme ve Diyetetik Bölümü, Ankara, Türkiye • 은tps://orcid.org/0000-0002-1235-0329

24th European Congress on Obesity, 2017, Porto, Portugal 'da poster olarak sunulmuştur.
3. Gazi Üniversitesi, Sağlık Bilimleri Fakültesi, Beslenme ve Diyetetik Bölümü, Ankara, Türkiye • 이 https://orcid.org/0000-0002-8784-3371

4. Gazi Üniversitesi, Sağlık Bilimleri Fakültesi, Beslenme ve Diyetetik Bölümü, Ankara, Türkiye • ๑ https://orcid.org/0000-0001-6356-5226

5. Gazi Üniversitesi, Sağllk Bilimleri Fakültesi, Beslenme ve Diyetetik Bölümü, Ankara, Türkiye • • () https://orcid.org/0000-0002-7930-9910 


\section{ABSTRACT}

Aim: To evaluate the satisfaction of employees with catering services, the factors that determine consumer meal satisfaction, and the practices for the protection and promotion of health in the workplace.

Subjects and Method: The study consists of 666 employees working in different public institutions in Ankara, [18-65 age range, 290 men (43.5\%), 376 women (56.5\%)]. The data were obtained through a questionnaire. A 39-question questionnaire was created in order to evaluate the satisfaction of the participants with the catering services. Questionnaire scores are classified as below 60 points as "unsatisfactory", 60-74 points as "moderate", 75-84 points as "good" and $\geq 85$ points as "very good". The internal consistency of the questionnaire was determined as 0.88 .

Results: The three most important factors affecting the satisfaction from catering services are hygiene (79.7\%), food quality (78.5\%) and the variety of the meals on the menu (51.2\%), respectively. Satisfaction with catering services was determined to be $65.8 \pm 11.87$ and the score was higher in men than women $(\mathrm{p}<0.05)$. While the frequency of individuals who evaluate their satisfaction as "very good" was $5.7 \%$, in the inadequate class was $31.7 \%$. Employees stated, $82.0 \%$ of the institutions do not have practices promoting healthy nutrition, and $69.0 \%$ do not offer potential opportunities for health promotion activities. Among the services to encourage healthy eating the three most common services are convenient facilities for hand washing (79.4\%), access to drinking water (67.0\%), and healthy food options (37.1\%).

Conclusion: The results show the necessity to implement standards for catering services in institutions and to increase the taste, quality and variety of meals in order to increase the satisfaction of the employees with the catering services. Therefore, workplaces should apply the Turkish Ministry of Health's guidelines for menu planning and healthy eating practices to have positive effects on employee's health, motivation and productivity.

Keywords: Catering services, consumer satisfaction, workplace health promotion

\section{GíRIŞ}

Çalışan bireyler günün büyük çoğunluğunu iş ortamında geçirmektedir, bu nedenle bireylerin sağlığının korunması ve teşviki konusunda kurumsal şartlar büyük önem taşımaktadır $(1,2)$. Dünya Sağlık Örgütü(3), işyerlerinde sağlığın teşviki ve geliştirilmesi amacıyla tütün ve madde kullanımı, sedanter yaşam tarzı, kötü beslenme, stres gibi davranışların azaltılması, çalışan sağlığının desteklenmesi üzerine odaklanılması gerektiğini belirtmektedir.

Çalışan bireyler işyerinde en az bir öğün (özellikle öğle öğünü) tüketmektedirler. Bu nedenle, kurumsal yemek hizmetlerinin kalitesi bireylerin yemek hizmetlerinden memnuniyet seviyelerini ve genel diyet kalitesini önemli ölçüde etkilemektedir (4,5). Aynı zamanda,yemekhizmetlerinden memnuniyetdurumu çalışanların motivasyonlarını ve iş performanslarını da etkileyen önemli bir etmendir. Kaliteli bir beslenme hizmeti veren toplu beslenme hizmetinin, çalışanların fizyolojik, sosyal ve psikolojik yönden tatmininde, üretkenliklerinde, verimliliklerinde, motivasyonlarında ve performanslarında artış ile kuruluşun başarılı olmasında etkili olabilmektedir (6).

Toplu yemek hizmeti sunumunda müşteri memnuniyetinin değerlendirilmesi, memnuniyeti etkileyen etmenlerin ortaya konulmasıyla mümkün olabilmektedir (7). Yiyecek içecek sektöründe müşterilerin memnuniyetini oluşturan faktörlerin belirlenmesine yönelik yapılan çalışmalarda müşteri memnuniyetini doğrudan veya dolaylı olarak etkileyen yiyecek kalitesi (hijyen, tat, besleyicilik, sağlıklı olması), hizmet kalitesi (servis, hız, iletişim), fiyatdeğer, yemek yenilen ortamın atmosferi (mobilyalar, ışıklandırma, duygular ve rahatlık) ve menü içeriği gibi faktörler değerlendirilmiştir (7-9). Bununla birlikte kurumun, sağlığın korunması ve geliştirilmesine yönelik uygulamalarının değerlendirdiği çalışmaların yapılması kurumun ihtiyaçlarının belirlenmesi 
ve farkındalığın oluşturulması açısından önem taşımaktadır. Bu çalışma, çalışan bireylerin kurumsal yemek hizmetlerinden memnuniyet durumlarını, tüketici memnuniyetini belirleyen faktörlerin ve işyerinde sağlığın korunması ve teşvikine yönelik uygulamaların değerlendirilmesi amaçları ile planlanıp yürütülmüştür.

\section{BİREYLER VE YÖNTEM}

$\mathrm{Bu}$ araştırma, çalışmaya katılmayı kabul eden 18-65 yaş aralığında gönüllü 666 kamu çalışanı üzerinde yürütülmüştür. Katılımcllar Ankara ilinde bulunan toplu beslenme hizmetleri veren kamu kurumlarında çalışan ve kurumlarında verilen bu hizmetlerden faydalanan gönüllü bireylerden oluşmuştur. Veriler, araştırmacılar tarafından yüz yüze yapılan bir anket aracılığıyla elde edilmiştir. Katılımcıların bilgilendirilmiş onamları alınmıştır. $\mathrm{Bu}$ araştırmanın yapılabilmesi için Gazi Üniversitesi Etik Komisyonu'ndan 77082166-302.08.01 sayı ile izin alınmıştır.

Anket formunda; katılımclların sosyo-demografik özellikleri, kurumun yemek hizmetleri ile ilgili genel bilgileri, kurumun sağlıklı beslenmeyi teşvik eden uygulama durumuna yönelik bilgiler ve katılımcıların yemek hizmetinden memnuniyetinin değerlendirilmesine yönelik sorular yer almaktadır. Ayrıca kurumun sağlıklı beslenmeyi teşvik eden uygulama durumuna yönelik 15 sorudan (düzenli olarak sağlıklı yaşam semineri/kursu hizmeti sunma, fiziksel aktivite alanları/spor salonu bulundurma gibi) oluşan bir form uygulanmıştır. Genel anket formunun içerisinde yer alan sağlıklı beslenmeyi teşvik eden uygulamalar bölümü bu konuda yapılan çalışmalar (10-13), literatür bilgileri ve T.C Sağlıklı Beslenme ve Hareketli Hayat Programı çerçevesinde öngörülen faaliyetlerden esinlenerek hazırlanan 15 sorudan oluşturulmuştur.

Katılımcıların kurumsal yemek hizmetlerinden memnuniyet durumlarının değerlendirilmesi amacıyla literatür taraması yapılarak 39 soruluk bir memnuniyet anketi oluşturulmuştur (14,15). $\mathrm{Bu}$ sorular ilgili kaynaklarda kullanılan sorulardan yararlanılarak ve literatür bilgilerine dayanarak hazırlanmıştır. İlgili kaynaklarda yer alan sorular bir ölçek niteliği taşımamaktadır. Bu çalışmada hazırlanan soruların iç tutarlılık analizi yapıldığında cronbach alfa değeri 0.88 ile ölçeğin güvenilir olduğu saptanmıştır (16). Belirlenen 39 soru; besin kalitesi (15 madde, örnek, yemeklerin tadı/lezzeti iyidir; yemekler içerik, renk, kıvam yönünden birbiri ile uyumludur gibi), menü kalitesi (8 madde; örnek, menülerde yer alan yemekler genel beslenme alışkanlıklarıma uygundur), yemek servisi kalitesi (5 ürün, örnek, yemek tepsisi, tabaklar, kaşıklar veya çatalların temizliği uygundur), personel hizmeti kalitesi (5 madde, örnek, yemeklerimi servis eden personel üniformalıdır ve temizdir), fiziksel çevre kalitesi (6 madde, örnek, yemek yediğim ortam yemek tüketimi için temizdir) sorularından oluşmaktadır. Her bir madde için 5'li likert ölçeği (her zaman/sıklıkla/ bazen/nadiren/asla) kullanılmıştır. Olumsuz sorular için ise puanlama ters kodlanmıştır ve tüm maddeler toplanarak 0-100 arasında ortalama memnuniyet skoru elde edilmiştir. Toplam memnuniyet puanı persentillere göre gruplandırılmıştır. İlk çeyrek Q1 (25. persentil) genellikle alt çeyrek, 50-75. persentil orta 75 ve üzeri üst çeyrek olarak adlandırılır (17). Bu doğrultuda toplam puan; 60 puanın altı ( $<25$. persentil) 'yetersiz', 60-74 puan (25-74. persentil) 'orta', 75-84 puan (75-94. persentil) 'iyi', $\geq 85$ puan ( $\geq 95$. persentil) ise 'çok iyi' olarak sınıflandırılmıştır.

\section{Verilerin İstatistiksel Değerlendirmesi}

Araştırma verilerinin değerlendirilmesinde SPSS paket programı 24.0 (Statistical Packages for the Social Sciences) kullanılmıştır. Tanımlayıcı veriler, ortalama ve standart sapma (SS) olarak verilmiştir. Cinsiyetler arası verilerin kıyaslanmasinda Independent Sample T testi kullanılmıştır. Kategorik değişkenleri karşılaştırmak için Ki-kare $\left(\mathrm{x}^{2}\right)$ testi uygulanmıştır. Sonuçlar \%95 güven aralığında, $\mathrm{p}<0.01$ ve $\mathrm{p}<0.05$ anlamlılık düzeyinde değerlendirilmiştir. 


\section{BULGULAR}

Bu çalışmaya 290 erkek (\%43.5), 376 kadın (\%56.5) olmak üzere 666 çalışan birey katılmıştır. Erkeklerin yaş ortalaması $36.3 \pm 9.5$ yıl olup kadınların yaş ortalamasindan $(32.2 \pm 7.9$ yll) yüksektir $(p<0.001)$. Katılımcıların \%63.8'i evli, \%59.6'sı ise üniversite mezunudur (tabloda gösterilmemiştir).

Bireylerin \%65.5’inin işyerinde yemek hizmetlerinden düzenli olarak yararlandığı, yararlanmayan bireylerin \%47.4'ünün yemekleri beğenmediği için tercih etmedikleri belirlenmiştir. Katılımcıların \%49.2'sinin kurumsal yemek hizmetlerinden hafta içi her gün yararlandığı ve işyerlerinin \%39.5'inin ücretsiz yemek hizmeti sunduğu, \%38.3’ünün ise ücretli ancak indirimli yemek hizmeti sunduğu bulunmuştur. İş yerinde sunulan menünün ise yaygin olarak (\%70.6) tabldot türü olduğu saptanmıştır (Tablo 1).

Bireylerin yemek hizmetlerinden memnuniyetini etkileyen en önemli faktörler sorgulandığında ilk üç sırada hijyen (\%79.7), besin kalitesi (\%78.5) ve menüde yer alan yemeklerin çeşitliliği (\%51.2) yer almıştır. Hijyen, besin kalitesi ve ekonomik faktörlerin cinsiyetler arasında fark gösterdiği bulunmuştur $(p<0.05$, Tablo 1). Kadın katılımcıların yemek hizmetlerinden memnuniyeti etkileyen en önemli faktörler açısından erkeklere göre hijyen ve besin kalitesine daha çok önem verdikleri saptanmıştır $(\mathrm{p}<0.05)$.

Yemek hizmetlerinden memnuniyet durumu skorları değerlendirildiğinde ortalama puanın $65.8 \pm 11.87$ (orta düzey) olduğu belirlenmiştir (Şekil 1). Memnuniyet skorlarına göre yemek hizmetlerini 'çok iyi' olarak değerlendiren bireylerin oranı \%5.7 iken, yetersiz olarak değerlendiren bireylerin oranı \%31.7’dir.

$\mathrm{Bu}$ çalışmada memnuniyetle ilgili en yüksek puan ortalamasina sahip olan alt boyutlar $3.8 \pm 0.96$ ve $3.7 \pm 0.79$ ile sirasıyla yemek servisi kalitesi ve fiziksel çevre kalitesi olarak bulunurken, en düşük puan

Tablo 1. Bireylerin kurumsal yemek hizmetlerinden yararlanma durumlarına ilişkin bilgiler

\begin{tabular}{|c|c|c|c|c|c|c|c|}
\hline & \multicolumn{2}{|c|}{ Erkek (n:290) } & \multicolumn{2}{|c|}{ Kadın (n:376) } & \multicolumn{2}{|c|}{ Toplam (n:666) } & \multirow{2}{*}{$\mathbf{p}^{*}$} \\
\hline & S & $\%$ & S & $\%$ & S & $\%$ & \\
\hline \multicolumn{8}{|c|}{$\begin{array}{l}\text { Yemek hizmetlerinden düzenli yararlanma } \\
\text { durumu }\end{array}$} \\
\hline Evet & 196 & 67.6 & 240 & 63.8 & 436 & 65.5 & \multirow{2}{*}{0.325} \\
\hline Hayır & 94 & 32.4 & 136 & 36.2 & 230 & 34.5 & \\
\hline \multicolumn{8}{|c|}{$\begin{array}{l}\text { Yemek hizmetlerinden düzenli yararlanmama } \\
\text { nedeni }\end{array}$} \\
\hline Pahalı olması & 16 & 17.0 & 12 & 8.8 & 28 & 12.2 & \multirow{5}{*}{0.155} \\
\hline Yemekleri beğenmemesi & 36 & 38.3 & 73 & 53.7 & 109 & 47.4 & \\
\hline Zaman yetersizliği & 12 & 12.8 & 20 & 14.7 & 32 & 13.9 & \\
\hline Sulu yemek sevmemesi & 2 & 2.1 & 3 & 2.2 & 5 & 2.2 & \\
\hline Ortamı beğenmemesi & 28 & 29.8 & 28 & 20.6 & 19 & 8.3 & \\
\hline \multicolumn{8}{|c|}{$\begin{array}{l}\text { Yemek hizmetlerinden memnuniyeti etkileyen } \\
\text { en önemli faktörler** }\end{array}$} \\
\hline Besin kalitesi & 216 & 74.5 & 307 & 81.6 & 523 & 78.5 & 0.026 \\
\hline Hijyen & 215 & 74.1 & 316 & 84.0 & 531 & 79.7 & 0.002 \\
\hline Servis yapan personelin tutumu & 65 & 22.4 & 67 & 17.8 & 132 & 19.8 & 0.140 \\
\hline Menüde yer alan yemeklerin çeşitliliği & 143 & 49.3 & 198 & 52.7 & 341 & 51.2 & 0.391 \\
\hline Ekonomiklik & 126 & 43.4 & 119 & 31.6 & 245 & 36.8 & 0.002 \\
\hline Hızlı servis & 50 & 17.2 & 52 & 13.8 & 102 & 15.3 & 0.225 \\
\hline Ortamin ambiyansı & 32 & 11.0 & 36 & 9.6 & 68 & 10.2 & 0.537 \\
\hline
\end{tabular}


Tablo 2. Yemek hizmetlerinden memnuniyetine yönelik alt boyutların ortalama ve standart sapma değerleri

\begin{tabular}{lccccccc}
\hline \multirow{2}{*}{ Alt boyutlar } & \multicolumn{2}{c}{ Erkek (n:290) } & \multicolumn{2}{c}{ Kadın (n:376) } & \multicolumn{2}{c}{ Toplam (n:666) } & \multirow{2}{*}{$\mathbf{p}^{*}$} \\
\cline { 2 - 7 } & Ortalama & SS & Ortalama & SS & Ortalama & SS & \\
\hline Besin Kalitesi & 3.6 & 0.72 & 3.4 & 0.78 & 3.5 & 0.75 & $\mathbf{0 . 0 0 5}$ \\
Menü Kalitesi & 2.5 & 0.78 & 2.4 & 0.77 & 2.4 & 0.78 & 0.066 \\
Yemek Servisi Kalitesi & 3.9 & 0.96 & 3.7 & 0.95 & 3.8 & 0.96 & $\mathbf{0 . 0 4 9}$ \\
Personel Hizmeti Kalitesi & 3.5 & 1.16 & 3.4 & 1.08 & 3.5 & 1.1 & 0.397 \\
Fiziksel Çevre Kalitesi & 3.8 & 0.75 & 3.6 & 0.82 & 3.7 & 0.79 & $\mathbf{0 . 0 0 1}$ \\
\hline
\end{tabular}

*Cinsiyete göre alt boyut puanları arasindaki farklar

Her bir alt boyuttaki maddelerin puanları toplanıp ve daha sonrasında madde sayısına bölünerek ortalama puan elde edilmiştir.

\section{Yemek hizmetlerinden memnuniyet durumu}

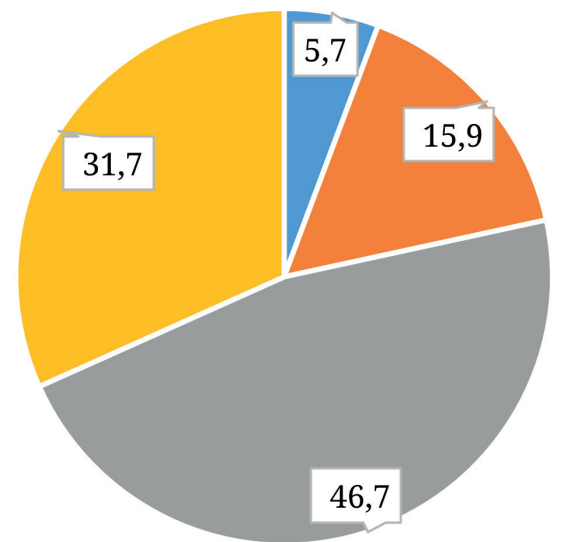

— Çok iyi $\quad$ İyi $\quad$ Orta $\approx$ Yetersiz

Şekil 1. Yemek hizmetlerinden memnuniyet durumu

ortalamasina sahip alt boyut ise $2.4 \pm 0.78$ puan ile menü kalitesidir. Besin kalitesi, yemek servisi kalitesi ve fiziksel çevre alt boyutları puanlarının kadınlarda daha düşük olduğu saptanmıştır ( $\mathrm{p}<0.05$, Tablo 2).

Erkeklerin toplam memnuniyet ortalama puanı $67.3 \pm 11.26$ (orta düzey), kadınların ise $64.7 \pm 12.21$ (orta düzey) olup aralarındaki fark istatistiksel olarak önemlidir ( $p=0.005$, Tablo 3). Medeni durum ve eğitim durumu açısından toplam memnuniyet puanları arasında önemli fark yoktur ( $p>0.05$ ) Aynı zamanda yaş, memnuniyet puanı ile düşük güçte pozitif bir ilişki göstermektedir $(\mathrm{r}=0.207 ; \mathrm{p}<0.001, \quad$ tabloda gösterilmemiştir).

Çalışanlara kurumlarının sağlıklı beslenmeyi teşvik eden uygulamaları hakkında bilgi ve düşünceleri sorgulandığında, \%82.0'sinde sağlıklı beslenmeyi
Tablo 3. Bazı demografik değişkenlere göre bireylerin yemek hizmeti memnuniyet puanı ortalama ve standart sapma değerleri

\begin{tabular}{lccc}
\hline & \multicolumn{2}{c}{ Toplam memnuniyet } & \\
\cline { 2 - 3 } & \multicolumn{2}{c}{ puanı } & p \\
\cline { 2 - 3 } Cinsiyet & & SS & \\
Erkek & 67.3 & 11.26 & \multirow{2}{*}{$\mathbf{0 . 0 0 5}$} \\
Kadın & 64.7 & 12.21 & \\
Medeni durum & & & \\
Bekar & 64.8 & 11.39 & 0.092 \\
Evli & 66.4 & 12.11 & \\
Eğitim durumu & & & \\
$\leq 8$ yll & 68.6 & 13.73 & \\
$>8$ yll & 65.6 & 11.72 & 0.110 \\
\hline
\end{tabular}

teşvik eden uygulamaların olmadığı, \%69.0'unda ise sağlığın teşviki ve geliştirilmesi faaliyetleri için potansiyel olanakların sunulmadığı saptanmıştır (Tablo 4). Kurumlarda, sağlıklı beslenmeyi teşvik etmeye yönelik hizmetler arasında en sık görülen üç hizmetin el yıkama için elverişli imkânların, sabun ve temiz havlu (\%79.4), tüm çalışanlar için içme suyuna erişim (\%67.0), çalışan restoranında sunulan sağlıklı yemek seçenekleri (\%37.1) olduğu belirlenmiştir.

\section{TARTIŞMA}

Karmaşık bir yapıya sahip olan beslenme hizmetlerini etkileyen pek çok faktör bulunmaktadır (18). Dubé et al. (19) yaptıkları çalışmada, hastaların beslenme servisinden memnuniyet durumlarını etkileyen yedi alt boyut belirlemişlerdir. Bunlar; besin kalitesi, 
Tablo 4. Çalışanların kurumlarındaki sağlıklı beslenmeyi teşvik eden uygulamaları hakkında bilgi düzeyleri ve düşüncelerine yönelik bilgiler

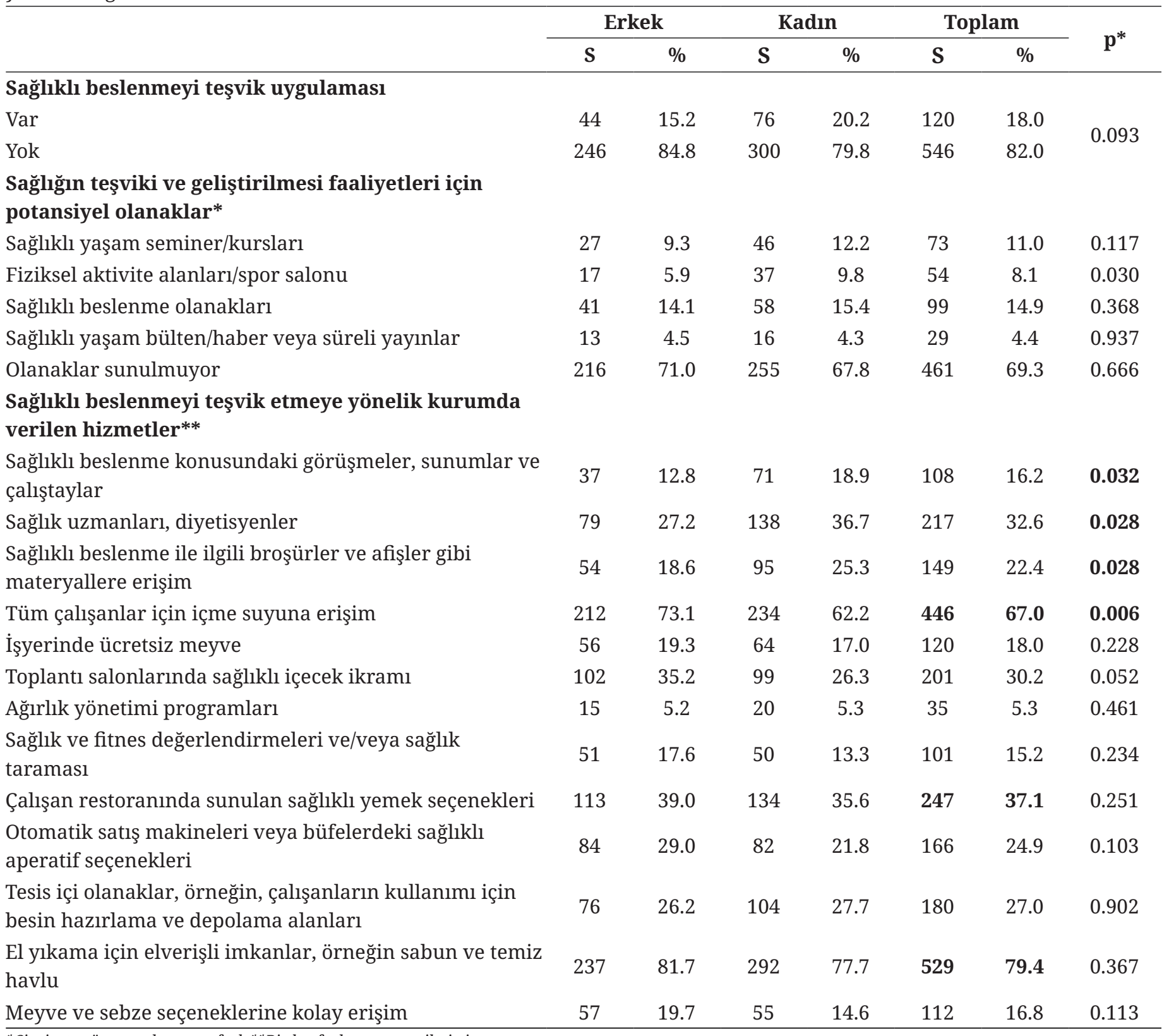

*Cinsiyete göre gruplar arası fark **Birden fazla cevap verilmiştir.

servis zamanlaması, servis güvenliği, yemeklerin ısısı, menü, yemek servis personeli ve kişiselleştirilmiş hizmet olarak bulunmuştur. Capra et al. (20) hastane beslenme servisinden memnuniyeti belirlemek üzere geliştirdiği ölçeğinde ise besin kalitesi, yemek servis kalitesi, servis/personel konusu ve fiziksel çevre olmak üzere dört alt boyut belirlenmiştir. $\mathrm{Bu}$ çalışmada araştırıcılar tarafından kullanılan memnuniyet anketi; besin kalitesi, menü kalitesi, yemek servisi kalitesi, personel hizmeti kalitesi, fiziksel çevre kalitesi olmak üzere beş ana başlıktan oluşturulmuş ve bu başlıklardan ayrı iki açık uçlu soru da dâhil edilerek toplam 39 soruyu içermiştir. Oluşturulan memnuniyet anketinin iç tutarlılığı 0.88 olarak bulunmuştur.

$\mathrm{Bu}$ çalışmanın sonucunda, kurumun yemek hizmetlerinden düzenli yararlananların oranının 
yüksek olduğu (\%65.5) ve bireylerin kurumsal yemek hizmetlerinden memnuniyet durumlarınin orta düzeyde (65.8 puan) olduğu belirlenmiştir. Yemek servisi kalitesi ve fiziksel çevre kalitesi alt boyutları en yüksek puanlara sahipken, en düşük puan ortalamasina sahip alt boyut ise menü kalitesidir. Yanık ve Yılmaz'ın (21) yaptıkları bir araştırmada, çalışanların yemek hizmetlerinden büyük ölçüde memnuniyetsiz oldukları ve katılımcların \%42.0'sinin başka kaynaklardan yemek temin ettiği belirlenmiştir. Kurumun yemek hizmetlerinden düzenli yararlanmama nedenlerinin başında ise yemeklerin beğenilmemesi yer almaktadır. Bir başka çalışmada ise Adıyaman Üniversitesi öğrencilerinin, akademik ve idari personelinin, hazır yemek hizmeti sunan yüklenici firmanın servis hizmetinden memnun oldukları, ancak sunulan yemeğin organoleptik özelliklerini yetersiz buldukları tespit edilmiştir (22). Benzer şekilde bu çalışmada, kurumun yemek hizmetlerinden yararlanmayan katılımcıların büyük çoğunluğu (\%47.4) "yemekleri beğenmediği için' tercih etmediklerini belirtmiştir. Katılımcıların yemek hizmetlerinden memnuniyet durumlarını etkileyen unsurlar sorgulandığında, en önemli faktörler sırasıyla hijyen, besin kalitesi, menüde yer alan yemeklerin çeşitliliği olarak belirtilmiştir. Müşterilerin memnuniyetini etkileyen faktörlerin belirlenmesine yönelik yapılan çalışmalarda da benzer şekilde hijyen, yiyecek kalitesi ve çeşitliliği ile fiyat ve fiziksel görünüm faktörleri öne çıkmaktadır $(7,23,24)$. Aynı zamanda bu çalışmada, kurumsal yemek hizmetlerinden memnuniyet puanı yetersiz olan bireylerin oranı \%31.7 ile önemli büyüklüktedir. $\mathrm{Bu}$ doğrultuda, kurumlarda yemek hizmetlerinden memnuniyeti arttırmak adına besin kalitesi ve çeşitliliğine daha çok önem verilmelidir.

Çalışmada, kadınların ortalama memnuniyet puanı erkeklerden daha düşük bulunmuştur $(p<0.05$, Tablo 3). Ayrıca, besin kalitesi, yemek servisi kalitesi ve fiziksel çevre alt boyutları puanları da kadınlarda daha düşüktür $(p<0.05$, Tablo 2). Kadın katılımcıların yemek hizmetlerinden memnuniyeti etkileyen en önemli faktörler açısından erkeklere göre hijyen ve besin kalitesine daha çok önem verdikleri saptanmıştır ( $\mathrm{p}<0.05$, Tablo 1$)$. Bu durum, kadınlarda yemek hizmetinden memnuniyet düzeylerinin erkeklerden daha düşük olmasını açıklayabilir. Katılımcıların medeni ve eğitim durumları yemek hizmetleri memnuniyeti ile ilişkili değildir ( $p>0.05$ ), ancak bekâr ve eğitim düzeyi $>8$ yll üzeri olan bireylerin memnuniyet puanları evli ve $\leq 8$ yl olanlara göre düşüktür (Tablo 3). Benzer şekilde yapılan bir araştırmada, personelin eğitim düzeyi yükseldikçe aldıkları yemek hizmetlerini olumsuz olarak değerlendirme oranlarının arttığı, bekar personel gruplarının evlilere göre daha fazla başka kaynaklardan yemek teminine yöneldikleri ve yaş ile memnuniyet düzeyleri arasında pozitif yönlü ilişki olduğu belirlenmiştir (21).

$\mathrm{Bu}$ araştırmada, çalışanların çoğunluğu (\%82.0), işyerlerinde sağlıklı beslenmeyi teşvik eden uygulamaların yapılmadığını belirtmişlerdir (Tablo 4). Yapilan uygulamalar arasında ise ilk iki sırada kurumun sağlıklı beslenme olanaklarını sunması ve sağlıklı yaşam seminer/kurslarının verilmesi olduğu görülmüştür. İşyerinde sağlığın teşviki ve geliştirilmesinde genel olarak tütün ve madde kullanımı, sedanter yaşam tarzı, kötü beslenme, stres gibi davranışların azaltılmasının teşviki ile sağlığın desteklenmesi amaçlanmaktadır (3, 25-27). Amerika Birleşik Devletleri'nde 2004 yılında 730 işyerinde yapılan Ulusal İşyerlerinde Sağlığın Teşviki Anketi (The 2004 National Workplace Health Promotion Survey) raporunda birçok şirketin sağlığın teşviki ve geliştirilmesine yönelik uygulamalar yaptığı, bunlar içerisinde destekleyici sosyal ve fiziki ortamın sağlanması (\%30) ile sağlık eğitimi verilmesinin (\%26) en yüksek oranda olduğu belirtilmiştir (10).

Dünya Sağlık Örgütü’nün (3) yayınladığı raporda, işyerlerinde sağlıklı beslenmeyi ve fiziksel aktiviteyi teşvik etmenin, pek çok araştırma sonucunda $(11,12,28,29)$ vücut ağırlığı, vücut yağ kompozisyonu, kan kolesterol düzeyleri başta olmak üzere antropometrik ölçümlerde ve kan parametrelerinde önemli olumlu değişiklikler saptandığı belirtilmektedir. Bu teşvik programlarının, 
yaşamsal ve iş memnuniyetini artırabildiği, alkol ve beslenme alışkanlıkları üzerine olumlu davranış değişiklikleri sağlayabildiğini ortaya koymaktadır. $\mathrm{Bu}$ değişikliklerin de işyerinde kaza ve hastalık maliyetlerinde azalmaya, üretkenlikte ve kazançta artışa yol açabileceğini göstermektedir (29). Bu nedenlerle, işyerinde sağlıklı beslenmeyi teşvik eden uygulamaların bulunması ve yemek hizmetlerinden memnuniyetin arttırılmasına yönelik plan ve politikaların uygulanması önem arz etmektedir.

Sonuç olarak; günümüzde hız kazanmış olan teknolojik gelişmeler ile birlikte çalışan sayısındaki artışa paralel olarak işyerinde toplu beslenme hizmetlerinin verilmesi zorunluluk haline gelmiştir. Birçok yetişkinin zamanının çoğunu geçirdiği işyerlerinde sağlığı geliştirici değişiklikler yapmak, insanların daha sağlıklı olmalarına yardımcı olmak için önemli bir yoldur. Bu doğrultuda işyerleri, T.C. Sağlık Bakanlığı’nın menü planlama ve sağlıklı beslenmeye yönelik rehberlerini uygulamalıdır (30). Türkiye Sağlıklı Beslenme ve Hareketli Hayat Programı kapsamında işyerlerinde sağlıklı menülerin sunulmasına ve işyeri fiziksel aktivite imkanlarının geliştirilmesine (ör. masa başında egzersiz) yönelik stratejiler bulunmaktadır (31). İşyerlerinde personele sağlıklımenülerin sunulması amacıyla Toplu Beslenme Sistemleri (Toplu Tüketim Yerleri) için Ulusal Menü Planlama ve Uygulama Rehberi'nin kullanılması ve yaygınlaştırılması önemlidir. Bu çalışmada, bireylerin yemek hizmetlerinden memnuniyetlerini etkileyen en önemli faktörlerin hijyenik kalite uygunluğu ve menü çeşitliliği olduğu görülmektedir. Bu doğrultuda yemek hizmetlerinden satın almadan servise kadar geçen süreçlerde güvenilir gıda üretimine yönelik standartlarin uygulanması, yemeklerde lezzetin, kalitenin ve çeşitliliğin arttırılması gereklidir. $\mathrm{Bu}$ kapsamda işyerlerinde diyetisyenlerin istihdamının sağlanması gerekmektedir. Personelin sağlıklı beslenmesi ve fiziksel aktivitesinin arttırılmasına yönelik planlanacak uygulamaların personel sağlığı, motivasyonu ve verimliliği üzerine olumlu etkileri olacağı ve işveren açısından da kazanç sağlayacağı unutulmamalıdır.
Çıkar çatışması - Conflict of interest: Yazarlar çıkar çatışması olmadığını beyan ederler. - The authors declare that they have no conflict of interest.

\section{KAYNAKLAR}

1. Bezerra IN, Curioni C, Sichieri R. Association between eating out of home and body weight. Nutr Rev. 2012;70(2):65-79.

2. Bozoglu M, Bilgic A, Yen ST, Huang CL. Household food expenditure at home and away from home in Turkey. In Selected paper prepared for presentation at the Agricultural and Applied Economics Association (AAEA) and CAES Joint Annual Meeting, Washington DC. August 4-6, 2013.

3. Quintiliani L, Sattelmair J, Sorensen G. The workplace as a setting for interventions to improve diet and promote physical activity. 2007. Geneva: World Health Organization. 2014. 1-36 p.

4. Ryu K, Han H. Influence of the quality of food, service, and physical environment on customer satisfaction and behavioral intention in quick-casual restaurants: Moderating role of perceived price. J Hosp Tour Res 2010;34(3):310-29.

5. Edwards JS. The foodservice industry: Eating out is more than just a meal. Food Qual Prefer. 2013;27(2):223-9.

6. Sezgin AC, Özkaya FD. Toplu beslenme sistemlerine genel bir bakış. Akademik Gıda. 2014;12(1):124-8.

7. Liang X, Zhang S. Investigation of customer satisfaction in student food service: An example of student cafeteria in NHH. Int J Qual Serv Sci. 2009;1(1):113-24.

8. Han H, Ryu K. The roles of the physical environment, price perception, and customer satisfaction in determining customer loyalty in the restaurant industry. J Hosp Tour Res. 2009;33(4):487-510.

9. Ryu K, Lee HR, Gon Kim W. The influence of the quality of the physical environment, food, and service on restaurant image, customer perceived value, customer satisfaction, and behavioral intentions. Int J Contemp Hosp Manag. 2012;24(2):200-23.

10. Linnan L, Bowling M, Childress J, Lindsay G, Blakey C, PronkS, et al. Results of the 2004 national worksite health promotion survey. Am J Public Health, 2008;98(8):15031509. -1509.

11. Engbers LH, van Poppel MN, Paw MJCA, van Mechelen W. Worksite health promotion programs with environmental changes: A systematic review. Am J Prev Med. 2005;29(1):61-70.

12. Park HS, Kim KI, Soh JY, Hyun YH, Jang SK, Lee S. Factors influencing acceptance of personal health record apps for workplace health promotion: Crosssectional questionnaire study. JMIR Mhealth Uhealth. 
2020;8(6):e16723.

13. Ross AM, de Saxe Zerden L. Prevention, health promotion, and social work: Aligning health and human service systems through a workforce for health. Am J Public Health. 2020;110(Suppl 2):186-90.

14. Hannan-Jones M, Capra S. Developing a valid meal assessment tool for hospital patients. Appetite. 2017;108:68-73.

15. Fitzgerald DM. 194 Hospital food-an evaluation of patient satisfaction with lunchtime meal and audit of compliance with standards. Age and Ageing. 2016;45(Suppl 2):13-56.

16. DeVellis RF. Scale development: Theory and applications. 4th ed. Los Angeles: Sage publications; 2016. p. 100-216.

17. Aczel AD, Sounderpandian J. Complete business statistics. Boston, MA: Irwin/McGraw Hill.1999. p. 20-25.

18. Hartwell HJ, Edwards JS, Symonds C. Food service in hospital: Development of a theoretical model for patient experience and satisfaction using one hospital in the UK National Health Service as a case study. Journal of Food Service. 2006;17(5-6):226-38.

19. Dubé L, Trudeau E, Bélanger MC. Determining the complexity of patient satisfaction with foodservices. J Acad Nutr Diet. 1994;94(4):394-401.

20. Capra S, Wright O, Sardie M, Bauer J, Askew D. The acute hospital foodservice patient satisfaction questionnaire: The development of a valid and reliable tool to measure patient satisfaction with acute care hospital foodservices. Food Res Int. 2005;16(1-2):1-14.

21. Yanık, A, Yılmaz E. Dışarıdan yemek hizmeti alınan bir eğitim ve araştırma hastanesinde personelin yemek hizmetlerinin değerlendirilmesi. Ejovoc. 2011;1(1):12639.

22. Çelik M. Müşteri memnuniyeti ve hizmet kalitesi üzerine Adıyaman Üniversitesi Yemekhanesi'nde bir uygulama. Adıyaman Üniversitesi Sosyal Bilimler Enstitüsü Dergisi.
2012;5(10):29-54.

23. Aksoydan E. Hygiene factors influencing customers' choice of dining-out units: Findings from a study of university academic staff. J Food Saf. 2007;27(3):300-16.

24. Okursoy A, Turan A. Açımlayıcı faktör analizi ve üniversite yemekhanesinde müşteri memnuniyeti üzerinde etkili olan boyutların belirlenmesi üzerine bir uygulama. Doğuş Üniversitesi Dergisi. 2013;15(1):65-78.

25. Harris JS, Fries J. The health effects of health promotion. In: O'Donnell MP, editors. Health promotion in the workplace. 3rd ed. Toronto: Delmar Thompson Learning; 2002. p. 1-22.

26. Law V. Health-Promoting Workplaces. In: Fong BYF, Law VTS, Lee A. Primary Care Revisited Singapore: Springer; 2020. p. 115-133.

27. Peters SE, Nielsen KM, Nagler EM, Revette AC, Madden J, Sorensen G. Ensuring organization-intervention fit for a participatory organizational intervention to improve food service workers' health and wellbeing: Workplace organizational health study. Journal of Occup Environ Med. 2020;62(2):e33-e45.

28. Shephard RJ. A critical analysis of work-site fitness programs and their postulated economic benefits. Med Sci Sports Exerc. 1992;24(3):354-70.

29. Matson-Koffman DM, Brownstein JN, Neiner JA, Greaney ML. A site-specific literature review of policy and environmental interventions that promote physical activity and nutrition for cardiovascular health: what works? Am J Health Promot. 2005;19(3):167-93.

30. T.C. Sağlık Bakanlığı. Toplu Beslenme Sistemleri (Toplu Tüketim Yerleri) için Ulusal Menü Planlama ve Uygulama Rehberi. Beyhan Y, Bilici S, Kızıl M. ed. Ankara: Anıl Reklam Matbaa; 2020. 540. s.101-121.

31. T.C. Sağlık Bakanlığı. Türkiye Sağlıklı Beslenme ve Hareketli Hayat Programı (2014-2017). Ankara: Anıl Reklam Matbaa; 2013. s. 101-62. 